\title{
The state of public health services in England - why hospital physicians should be worried
}

\author{
Author: John R Ashton ${ }^{\mathrm{A}}$
}

'The Health of the People is the Highest Law' proclaims the legend on a plinth above the doorway of Southwark Town Hall on Walworth Road. Taken from Cicero's De-Legibus book, this succinct claim not only makes clear the importance attached to public health in ancient Rome but also reminds us that in its heyday public health in local authorities in the UK was a force in the land. I am reliably informed by former Manchester chief environmental health officer, Mike Eastwood, that when he began his training in the Public Health Department in Liverpool in 1974, the city's last medical officer of health, Dr Andrew Semple, had responsibility for over 5,000 staff. In addition to community nurses, health visitors, community medical officers, social workers and environmental health officers, this formidable team included vets, food hygiene inspectors, abattoir managers, chemical analysts and many more. Semple played a key role in post-war slum clearance policy and the development of a huge public housing stock built to Parker Morris standards, including the provision of larger four-bedroom houses with garages for local GPs. I mention this, not out of any romantic nostalgia to turn the clock back to an idyllic age of enlightened paternalism, but to remind us of the wide range of determinants of health and the importance of tackling them systematically. This idea is not new.

According to Charles Winslow, the founder of Yale School of Public Health in 1915, 'public health is the science and art of preventing disease, prolonging life and promoting physical health and efficiency through organised community efforts for the sanitation of the environment, the education of the individual in principles of personal hygiene, the organisation of medical and nursing service for the early diagnosis and treatment of disease, and the development of the social machinery, which will ensure to every individual in the community a standard of living adequate for the maintenance of health'.

The need for a national health service to achieve this was made explicit for the UK in the Beveridge report of 1942, which to a large extent represented a consensus brought about by the appalling effects of the recession in the 1930s. The plan for the post-war welfare state was put forward as part of an attack on the Bunyanesque 'five giant evils': want, disease, ignorance, squalor and idleness.

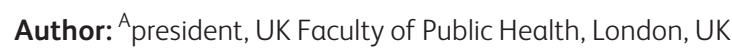

The NHS, which formed in 1948, was intended as one major plank of post-war reconstruction, reflected in other countries and through the creation of the United Nations (UN), the World Health Organization and other UN agencies, to address the root causes of social instability, conflict and war. When it was implemented, the NHS had what was described as a tripartite structure, consisting of the existing wartime networks of poor law and municipal and university hospitals, family doctors, opticians, pharmacists, dentists and other community health services, including maternal and child health clinics and venereal disease clinics, together with the rest of the third arm of the NHS - local authority public health departments.

For many years, commentators appear to have lost sight of this profoundly important concept of an integrated tripartite set of arrangements. Perhaps it was inevitably lost in the aftermath of 1974 , and it was not without its critics at the time, but in many ways we are still struggling to recreate it, not least with the Five Year Forward View, New Care Models, the move of part of public health back into local authorities and the emphasis on integration.

Underlying the decline of public health in the post-war period was a sense that the historic mission of public health - dealing with the infectious diseases - had been achieved. The 19th century scourges of typhus, typhoid, cholera and tuberculosis, together with the plethora of childhood infectious disease threats, were in retreat and it became fashionable to believe that the future lay with the ascendant pharmaceutical industry producing 'a pill for every ill' based not only on such seemingly magical breakthroughs as insulin and antibiotics, but also the anxiolytics, antipsychotics and antidepressants that held out the promise of a revolution in mental healthcare and deinstitutionalisation. It was indeed argued that epidemiology was inherently about infectious disease and it was inappropriate to talk of it in the context of non-communicable diseases and long-term conditions.

We are now well aware of the fallacy of such thinking and that a public health approach focusing on populations and deploying the rich methods of population analysis and intervention are as applicable to cancer, heart disease, alcohol, drug abuse, teenage pregnancy and violence as to HIV and Ebola (although it still occasionally happens that public health is pigeonholed in a place called 'drains'). When clinicians and population health specialists work together, whether it be on syringe exchange in Liverpool in the 1980s, Keith Ball with his work on coronary prevention in London, Hugh Jackson on 
child accident prevention in Newcastle, Jonathan Shepherd with his work on the prevention of facial injuries in bars in south Wales and elsewhere, or the concerted efforts of volunteers in Sierra Leone, mountains can be moved.

Writing at the dawn of 2016 about the state of public health in England (it is in a different place in the remainder of the UK as the systems continue to diverge), it is in a Dickensian sense 'the best of times and the worst of times'. It is the best of times inasmuch as there is massive interest in public health, not least in the mass media, which is very comfortable talking about modern public health as including the aforementioned topics. Over the past 25 years we have opened up careers in public health to those without a medical background and now have a remarkably diverse group of very able young people coming through, as well as the richness of genuinely multidisciplinary teams of equals working together in a common cause across the country.

As president of the faculty of the three medical royal colleges with responsibility for public health and as a member of the council of the Academy of Medical Royal Colleges, I have been greatly encouraged by the support for public health from colleagues. Ian Gilmore, a previous president of the Royal College of Physicians (RCP), is one of many physicians who have championed public health; in his case, through campaigning about alcohol. It is notable that the RCP has published a landmark report on air pollution. It is my realistic dream that each college will, in the near future, produce such reports relevant to their own areas of activity. Certainly, many colleges wish to strengthen the public health content of their curricula. I am regularly asked by those in training about the prospects for dual qualification, hybrid, population and clinical careers.

On the ground the picture is mixed. The fallout from Andrew Lansley's ill-conceived reorganisation of the NHS continues. Whether or not, as many believe, the destabilisation of the NHS was a prelude to privatisation, it has resulted in various types of chaos over and above its impact on hospital services and general practice. There is fragmentation, duplication, a mayhem of organisations, confusion and a crisis of morale. For those in public health in local government, while for some it seems to be working, for others their teams have been decimated, terms and conditions changed, budgets cut and so-called ring-fenced budgets used to balance the books for other local authority functions.

On one level, given the decimation of local authority budgets by central government, this is understandable, even while the Orwellian double speak of devolution is not. On the other hand, the removal of $£ 200$ million from a pathetic global sum for public health at short notice in the current financial year, followed by further annual cuts, as announced in the recent Comprehensive Spending Review, totalling over $20 \%$ in the lifetime of the parliament, makes no sense.

The evidence is rock solid that investing in public health saves the NHS money: for every $\mathfrak{£} 1$ we spend on sexual health services, we save $£ 11$. Diabetes, heart disease and obesity all cost the NHS millions of pounds a year to treat; yet preventing them by investing in public health measures would ease pressure on the NHS.

From the point of view of the organisational arrangements for public health, we now have a dystopian new version of tripartite with budget cuts leading to a reduction of the capacity in local government and a steady drift of our medically qualified consultants to other sectors, not least to Public Health England (PHE) where NHS consultant terms are protected, the availability of public health advice both within and to both hospitals and primary care (healthcare public health) has all but disappeared.

In 2013, we called for PHE to be established as a body independent of government as we believed this was in the best interests of the public's health. Our position in this regard has not changed: we know government is influenced by industry and economic concerns and I worry that these take precedence over the health of the people. We need a strong, independent public health profession to challenge government thinking and provide best available evidence for effective government policy that protects and improves the public's health.

From a technical point of view, PHE - together with NHS volunteers - played a crucial role in the Ebola emergency in Sierra Leone. However, it remains to be seen whether PHE can satisfy its critics as to its closeness to government and ability to demonstrate that it is a robust and independent voice for public health that speaks truth to power. The Faculty of Public Health and other royal colleges also have a strong role to play in being a 'critical friend' to governments so they are encouraged to take bold, evidence-based policy decisions. An early test will be how the forthcoming strategy on obesity is enacted.

The recognition of the issues facing public health by clinical colleagues and by members of the Academy of Medical Royal Colleges in recent months has been most impressive. Clearly there is recognition that unless upstream work and secondary prevention is effective on tackling health inequalities, the challenges facing physicians will be all the greater. It is in everybody's interest to have an effective, coherent and fully funded public health system. Without it, we will have failed not only Cicero but all those giants who paved the way for the achievements of the post-war settlement.

The Health Select Committee under the able chairmanship of Dr Sarah Wollaston is to examine the public health function since 2013 in the coming months. I would encourage all those with an interest in resolving the situation to make their voices heard. We are all in public health now!

Address for correspondence: Professor ] R Ashton, Faculty of Public Health, 4 St Andrews Place, London NW1 4LB, UK. Email: johnrashton@blueyonder.co.uk 